Global Internet Governance Academic Network (GigaNet) Third Annual Symposium, Hyderabad, India, December 2, 2008

\author{
Panel 2: Networked Governance Theories and the \\ Institutionalization of Internet Governance
}

\title{
New web standards in the making: Transnational private governance and beyond $^{1}$
}

\author{
François-Xavier \\ DUDOUET \\ IRISES (UMR CNRS 7170), \\ Université de Paris-Dauphine, \\ Pl. Maréchal de Lattre de Tassigny, \\ 75775 Paris Cedex 16 \\ Tel: (33) 144054069 \\ dudouet@dauphine.fr

\section{Benjamin} \\ NGUYEN \\ Laboratoire PRiSM (UMR CNRS 8144), \\ Université deVersailles St-Quentin, \\ 45, av. des Etats-Unis, \\ 78035 Versailles, FRANCE \\ tel: (33) 139254049 \\ benjamin.nguyen@prism.uvsq.fr \\ W3C Advisory Comity Representative for Univ. Versailles St-Quentin
}

\section{Antoine}

\section{VION}

LEST (UMR CNRS 6123)

Université de la Méditerranée

35, av. Jules Ferry,

13626, Aix-en-Provence Cedex, FRANCE

tel: (33) 491360302

antoine.vion@univmed.fr

4S Member

${ }^{1}$ This work was partially funded by the French ANR-05-JCJC-0205 Jeunes Chercheurs 'WebStand". 


\begin{abstract}
Our paper presents empirical results of a study on the bargaining process of web XML standards in World Wide Web Consortium (W3C) arenas. Processing the 8 main mailing lists, constituted of more than 21000 mails, has led us to analyze the standardmaking process through the bargaining habits and networks of actors who take part in it. It often appears that institutions interacting the most with others directly take part in the writing of final texts, and that firms often intend (and manage !) to play a leading role in this work.
\end{abstract}

In the field of internet, "networked governance refers to a growing body of research on the interconnectedness of essentially sovereign units, which examines how those interconnections facilitate or inhibit the functioning of the overall system." (Lazer, 2007). It supposes that State actors play a big role in the construction of rules and standards, though they have to cooperate with many other actors through networked organizations. On the contrary, transnational private governance refers to "the ability of non-state actors to cooperate across borders in order to establish rules and standards of behaviour accepted as legitimate by agents not involved in their definition. Non-state actors not only formulate norms, but often also have a key role in their enforcement. Accordingly, the current privatization of rule-making and enforcement goes much further than traditional lobbying in allowing private actors an active role in regulation itself" (Graz, Nolke, 2007). In this pattern, governance is based on interconnections and interdependences which are mostly made of nonsovereign units, and public regulation by agencies or so on is reduced to a strict minimum.

In our case study, the whole process from the W3C common work to the ISO struggle illustrates the ambiguity of transnational private governance: on the one hand, competition between firms is only made possible by cooperative work. On the other hand, such a relation shows its limits when firms try to convert web standards into software standards which could become quasi-monopolistic on the mass-consuming software market in the future. Unsurprisingly, the end of 'coopetition' is marked by conflicts and harsh industrial competition, which impose arbitrations and may reveal the need for public regulation such as ISO. This generates both inflexions in transnational private governance and deep transformations in the traditional interagency pattern of standardization.

\title{
KEY WORDS
}

Activism, Controversies, Coopetition, Corporate rulers, Critique, Debates, Governance, Institutions, Influence, ISO, Key Actors, Key Arguments, Social Networks, Standardization, Transnational Private Governance, XML, XQuery, W3C. 


\section{INTRODUCTION}

Governing internet is a growing concern for social scientists, as it implies altogether new technologies and property rights ${ }^{2}$, new ways of knowing and communicating ${ }^{3}$, new kinds of governance (Kleinwächter, 2007 ; Bedenek, Kettermann, Bauer, 2008), new patterns of democracy and participation (Korff, Gellner, 1994 ; Bimber, 1998 ; Jennings, Zeitner, 2003 ; Taubman, 2003, Sunstein, 2007), and new business models (Iansiti, Mc Cormack, 1997 ; Werback, 2000 ; Chesbrough, Appleyard, 2007 ; Pisano, Teece, 2007 ; Paraponaris, 2008). In this paper, we focus on the ways and procedures through which web standards are defined, in order to explore another dimension of governance that may be qualified as one of the many "black holes of power" in the era of globalization (Lascoumes, Lorrain, 2007).

\subsection{The decisive role of new web standards in the governance of internet}

We assume that standardizing new web languages is all the more important since it determines the renewing structural conditions of exchange over Internet, like HTML and IP protocols did when the World Wide Web emerged. This is why we consider the standardization of XML as a central case study for prospective views on internet governance. XML is a semi-structured format mainly used to exchange information between applications on the web, which is highly flexible. It represents semistructured information in which structured data (e.g., for each message, e-mails and dates) can be mixed with raw text (message body), images, and so on. It is flexible and evolutive: new information can be added at will by adding new elements or attributes. $\mathrm{XML}$ is intended to be the new language of the Web making it suitable to the writing of wrappers for Web pages or other data found on the Web. This new language was adopted through a very specific (and long) process of standardization that we want to explore here.

Generally, standards refer to voluntary technical specifications explicitly documented and published as tools used in the organisation of production and exchange of goods and services. Standards codify technical specifications regarding measurement, design, performances, or side effects of products, industrial processes, services, medical protocols, and so on. All of them involve ongoing struggles between multinational enterprises, organised interests, professional powers and state regulators. Though sociological studies were conducted on standardization processes, business and economic studies still tend to dominate the field.

Schumpeter pointed out that in the capitalist reality the major way of competing is not by assuming classical price competition but by producing innovative goods and processes. As innovation requires investing huge financial resources without immediate gains (negative cash-flow), it can only be assumed when pay-back is guaranteed some sort of monopoly (including patents, licensing and so on). Indeed, if any innovation could be freely appropriated, only a monopolistic firm would find it attractive. Except libertarian ones, most economists follow Schumpeter, but deal differently with his work in their studies.

2 e.g. (Kavassalis et al., 1996 ; Mueller, 2002 ; Jullien, Zimmermann, 2006)

3 e.g. (Beaudouin Velkovska, 1999 ; Beaudouin et al., 1999 ; Di Maggio et al., 2001 ; Auray et al., 2007) 
A first trend in contemporary studies consists on balancing incitation to increase benefits from patenting innovations, and incitation to adopt standards which would limit financial risks associated to standardization. Actually, though a new standard does not mean exclusive benefit, it can be seen as a kind of collective appropriation of new formats which imposes designations and uses that structure new markets excluding any other alternative than a rival market. In the field of ICT, recent studies tried to measure the quantitative evolution and the process of intellectual capital accumulation from a technological generation to another (Bekkers, West, 2006). What appears is that firms increasingly constitute patent pools in order to guarantee investment in new products or adoption of new standards. A major concern of these studies is to enable firms to "navigate the patent thicket" (Shapiro, 2001 ; Lerner, Tirole, 2004). Let us stress that this model is only partially relevant for computer science technologies where open source software may simplify intellectual property rights problems, even though such technologies meet the same interoperability difficulties as classical standards (Jullien, Zimmermann, 2006).

Such problems are called "network effects" in the classical literature about standards. In these studies, the concept of a network is very general. It only means a set of agents choosing a given technology on the basis of its interoperability benefits. The main hypothesis in this case is that a network externality may exist as soon as new participants do not manage to internalize the impact of a new network on new agents. Such an externality is positive if the private value produced is inferior to the social value of the network. In this case, the problem is that marginal followers may hope better investment pay-backs than pioneers. This may lead to a situation in which pioneers would adopt a standard corresponding to inferior technological solutions, in order to limit risks (Katz, Shapiro, 1985 ; Farrell, Saloner, 1985, Besen, Farrell, 1994). Further developments of "network effects" literature showed that this effect might be internalized by "sponsored standards", what means standards that guarantee private income through restricted uses and IPR (patents or licensing). (Liebowitz, Margolis, 1994, 1995). Theoretically, this field explored a vast set of questions such as problems of equilibrium in initial choice of standards (Katz, Shapiro, 1985, 1994 ; Besen, Farrell, 1994), market failures (Farrell, Saloner, 1985 ; Katz, Shapiro, 1994, Gröhn, 1999 ; Stahn, ), instability of market concerned by network effects (Farrell, Saloner, 1985; Besen, Farrell, 1994; Shapiro, Varian, 1998), or technological path dependency (Liebowitz, Margolis, 1994, 1995).

In this literature, debates on market equilibriums and market failures in models with $n$ agents do not meet the question of the embedding of market regulation in structures of governance. As soon as one considers standards as available goods on a market, they miss the specific dynamics of innovation marked by a long-standing process of inter-firm cooperation which may be institutionalized despite competitive conditions of exchange remaining active. Such a process corresponds to the concept of 'coopetition' (Brandenburger et Nalebuff, 1995 ; Nalebuff, Brandenburger, 1996, 1997). In this study, we try to analyse the adoption of XML standards both from its dimension of institutionalized modes of governance and its dimension as "coopetition game". 
About governance, little is known about the ways experts concretely interact and structure standardization arenas (Tamm-Hallström, Demortain, Dudouet, Vion, et al.), except the well-known field of accounting standards (Simmons, 2003). About internet, studies dealing with standardization focus more on contents and exchange rules than on integrative languages which determine them. Yet, the success of innovative technologies depends on their widespread adoption which in turn depends on their recognition as a standard. Let us stress that recommendations such as those issued by the W3C, although not formal standards technically speaking are de facto standards once they are adopted by a worldwide user or industrial community (Dudouet, Mercier, Vion, 2006).

This is why we focus on coopetition as a social mechanism which allows the adoption of recommendations defining common web languages. Henceforth we will use the term standard to refer to such technical documents.

The role of the sociologist in standard-setting bodies such as the W3C is obvious: such bodies are concerned with the usability and accessibility of Web technologies to the greatest possible number of people. Understanding the processes of communication, technical initiatives and standard production is useful for any organization (academic or corporation) with a focus on Web technology. Such an understanding is equally useful for the standardization body itself as it can lead to improved procedures or explain them better.

\subsection{Methodology of our case study}

This study mainly proposes microstructural approaches based on network analyses. Such analyses are conducted here in order to correlate measures of activism and measures of social influence on the final recommendations (Dudouet, Nguyen, Vion, et al. 2007). Further comments are made on the basis of more qualitative research about controversies and critiques between IBM and Microsoft about the standard-making process in ISO (Dudouet, Vion, 2007), and voting in national agencies (Diaz, 2008).

First, we intend to manage some sort of multi-level analysis ${ }^{4}$ by observing the concrete activity of experts of the W3C and then by searching for their ties with companies or any other institutions concerned with innovation. Such a method leads to deeper analyses and systematic measures of the structural dynamics of the standardization work investigated by Tamm-Hallström $(2001,2004)$ or Graz (2006).

The activity of experts mainly consists of arguing and bargaining on mailing lists in which recommendations for standards are debated. These recommendations become statutes for programmers. The W3C public working group pages capture communication interaction between different people (called actors in the following, and modelled as entities) and trace their actions, positions and declarations through time. These Web-based information sources inform the sociologists about the interactions

\footnotetext{
${ }^{4}$ Hox and Kreft (1994) proposed a smart survey about multi-level analysis, and the use of such methods in sociological inquiries. The main problem is of course managing the variation of contexts when jumping from individual behaviours to - for example - institutional patterns. From this perspective, see our first results below.
} 
between actors of a given process ${ }^{5}$. In the particular case of elaborating web standards, mailing lists are all the more interesting since they are becoming the prevalent means of interaction between participants scattered around the globe and working in different time zones. Moreover when participants do actually meet physically or attend teleconferences, written notes of the meeting or teleconference are taken and usually published on the Web shortly afterwards. A social scientist studying the standardization process must adapt to this situation by developing and using computerized data management tools since techniques such as manual interviews and information collection become powerless to apprehend the sheer size of the corpus.

Our research process aims at investigating the structure of interactions on mailing lists, in order to understand who leads the discussions, both qualitatively (pragmatic analysis) and quantitatively (network analysis). Both aspects need to be related. Quantitative analysis mainly consists on counting the numbers of e-mails sent on mailing-lists by individual actors, actors from a given institution, etc. This gives first indications on the level of personal investments in this activity. For this paper, we present the quantitative work, and how we went back from mailers to institutions (firms, research centres, NGOs, etc.) the actors were linked to. We then pay attention to the way technical solutions are debated in the W3C and ISO forums.

Following the XML standardization process is a big challenge in terms of data warehousing and data mining. Documents as formal as W3C recommendations represent tens of thousands of pages in a simple World format. Since we had to deal with about 20.000 mails and around 3.000 email authors, no manual work could be done. Therefore we built a specific conceptual model, which may have further applications for various other sociological enquiries based on large groups of people communicating via emails or forums (Colazzo, Dudouet, Manolescu, Nguyen, Senellart, Vion, 2008). Our aim was to identify which institutions were the most implicated in the standardization process. The data we present is not the final results of the study. Indeed, temporal variations are not sufficiently taken into account at this step of the process. As our results are still too synchronic, we prefer talking about first observations that guide the future developments of the research process.

The corpus by now is composed of 8 public mailing-lists of the W3C, which have been active from 1999 to 2006 and we extracted automatically and fully. In addition, we have made an inventory of the technical preconizations ${ }^{6}$ produced in connection with these lists. The chosen lists were about the XML standard, as it allowed us to have a good control and knowledge of the data for a first experimentation. The first range of investigations consisted on measuring activism on these lists. Note that these results are a continuation of our work exposed in (Dudouet et al., 2005), where we focused exclusively on the public-qt-wg mailing list. We considered as active the participants who posted at least 20 messages on a mailing-list. We obtained 72 actors who sent 10619 messages on 8 lists, which represents $61 \%$ of the total interactions.

\footnotetext{
5 A few available studies have explored the social uses of mailing lists from the perspective of posting habits (Buckner and Gillham, 1999; Dudouet et al., 2005), sociality rules (Beaudouin, Velkovska, 1999), or network structure and ethnology (Auray, Dorat, Conein, Latapy, 2006).

${ }^{6}$ By technical preconizations, we include: official recommendations of $\mathrm{W} 3 \mathrm{C}$, drafts, which are supposed to become such recommendations, and Working Group notes.
} 
In order to analyze these mailing lists, we built a semi-structured database on the key actors of the standardization process of the World Wide Web Consortium (W3C). Finally, a big part of the study presented here was still done manually, as the automatic extraction only covers the public mailing lists of the W3C. Furthermore, everything we say about ways of knowing and arguing and ISO struggles is based on a more qualitative enquiry which is still in its enfancy. The second part of the study is based on a qualitative work in progress ${ }^{7}$, and on a cooperation with Scholars from the University of Lausanne (Diaz, 2008).

\subsection{Outline of the paper}

In section 2, we introduce the discussion about the kind of structure in which the governance of standardization is embedded. We examine two models of governance: networked governance (NG) and transnational private governance (TPG). In section 3 , we examine the way through which the making of web standards gets controlled by corporate rulers within a global frame of Transnational private governance (TPG). In section 4, we show that the turn of the standardization process towards a more classical regulation (ISO procedure) stresses the limits of TPG, and the need for new rules, which are still to be defined.

\section{THE COORDINATION OF WEB STANDARDIZATION: 'NETWORKED GOVERNANCE' OR 'TRANSNATIONAL PRIVATE GOVERNANCE'?}

"Governance in a world where boundaries are largely in flux is being shaped and pursued in constellations of public and private actors that include states, international organizations, professional associations, expert groups, civil society groups and business corporations." (Djelic, Sahlin-Andersson, 2006). Following this definition of governance, the question is how far networks are inclusive and controlled by State authorities. Taking a look at concrete processes of standardization of new web languages, we will try to answer this question and to show how networks and their resources change along time.

We will not only pay attention to the ways people bargain or argue, but map their structures of interactions. This approach is based on what Granovetter (1992) calls 'structural embeddedness' rather than 'relational embeddedness', what means that similar outcomes may be expected from structurally similar positions, and that structurally equivalent actors recognize each other as comparable (even if they haven't met) and imitate aspects of each other (Burt, 1987), such as what Powell and Di Maggio (1992) called 'mimetic isomorphism'. On the contrary, relational embeddedness means a tighter focus on interpersonal transmissions and ties in which resources flow as flux in 'pipes' (Podolny, 2001 ; Borgatti, Foster, 2003). Even if the two dimensions may be present in social studies, let us note that the two approaches differ on the way they define resources. In relational approaches, resources get created and valued through relations, while they are predefined by social conditions according to structural approaches. In the field of Science and Technology Studies, Kleinmann

\footnotetext{
7 A previous version of this part was presented at the 4S Congress, Montreal, September 2007 (Dudouet, Vion, 2007).
} 
understands structures as "specific formal or informal, explicit and implicit rules of play which establish distinctive resource distributions, capacities, and incapacities, and define specific constraints and opportunities, for actors depending on their structural location” (Kleinmann, 1998 ; Klein, Kleinmann, 2002).

This focus on rules, resources and constraints as social mechanisms emerging from specific conditions of exchange meets growing concerns about structural embeddedness of governance. In their effort to define a new type of governance embedded in global networks, what they call "network governance", Borgatti et al. (1997) insist on four exchange conditions (demand uncertainty, task complexity, human asset specificity and frequency) through which governance is embedded in social mechanisms such as a restriction of the access to networks, the growing importance of collective sanction and reputation, and new macro-cultural patterns (e.g. open source licensing, free downloading, and so on) (see Table 1). In this model, the main characteristics of social control remain a kind of collective functioning which may be guaranteed by the State if needed. More recently, "networked governance" was more explicitly defined as "a growing body of research on the interconnectedness of essentially sovereign units, which examines how those interconnections facilitate or inhibit the functioning of the overall system." (Lazer, 2007). It supposes that State actors play a big role in the construction of rules and standards, though they have to cooperate with many other actors through networked organizations.

On the contrary, transnational private governance refers to "the ability of non-state actors to cooperate across borders in order to establish rules and standards of behaviour accepted as legitimate by agents not involved in their definition. Non-state actors not only formulate norms, but often also have a key role in their enforcement. Accordingly, the current privatization of rule-making and enforcement goes much further than traditional lobbying in allowing private actors an active role in regulation itself' (Graz, Nolke, 2007). In this model, exchange conditions are completely different, because they are based on a quick transformation of the organization of markets, which incite big firms to coordinate, cooperate to limit competition and sustain global value chains. In such a model, formal and informal procedures are no longer controlled by State authorities (Hall, Biersteker, 2002) but by actors who control social mechanisms such as financial capabilities and expert credibility, and are able to enforce rivals or mobilize loyalties within industrial or trading coalitions (see Figure 2).

In this study, we show that the governance of web standards is more likely to be analyzed through the TPG model than through NG model. Empirically, it often appears that institutions interacting the most with others directly take part in the writing of final texts, and that firms intend (and manage !) to play a leading role in this work. This is due to the human and financial resources firms are able to mobilize in such processes. Sheila Jasanoff (2003) wondered whether many scientific innovations were not wholly controlled by "corporate rulers", who would only have to face the critiques of consuming citizens. In this study, we will show that the XML standardization process can indeed be seen as a process controlled by "corporate rulers", in which critiques from consuming citizens are only represented by few researchers from public centers (whose oppositions are somehow domesticated through formal procedures of debate) or self-appropriated by firms themselves. 
Figure 1. How interaction of exchange conditions lead to structural embeddedness in network governance (Bargotti et al., 1997)

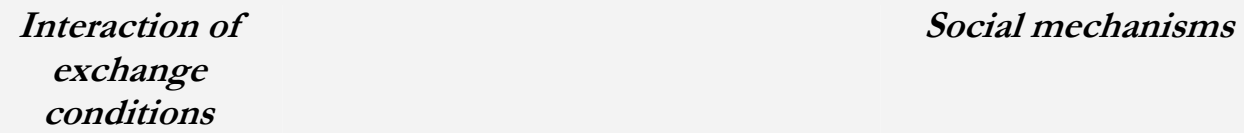

\begin{tabular}{|l|l|l|}
\hline $\begin{array}{l}\text { Demand } \\
\text { uncertainty } \\
\text { Task complexity } \\
\begin{array}{l}\text { Human Asset } \\
\text { specificity }\end{array} \\
\text { Frequency }\end{array}$ & $\begin{array}{c}\text { Structural } \\
\text { Embeddedness }\end{array}$
\end{tabular}$\quad \Rightarrow \quad \begin{aligned} & \text { Restrictive access } \\
& \text { Macroculture } \\
& \text { Collective sanction } \\
& \text { Reputation }\end{aligned}$

Figure 2. How interaction of exchange conditions lead to structural embeddedness in transnational private governance (inspired by Graz and Nölke, 2007)

\section{Interaction of exchange conditions}

Transformation in the organization of markets

Heavy coordination mechanisms

Limited competition (oligopolistic)

Dependency on global value chains
Social

mechanisms

Formal and informal procedures

Financial capabilities and leverage power

Use of force/loyalty

Credibility 


\section{STANDARDIZING XML IN W3C WORKING GROUPS: A TRANSNATIONAL PRIVATE GOVERNANCE MODEL}

Elaborating new web languages is a central activity of the World Wide Web Consortium (W3C). The major part of the work in W3C is made through mailinglists, which are of two kinds:

1) Private mailing-lists are somehow reserved to communications between top experts identified by the Consortium. For confidentiality reasons, we cannot access this forum.

2) Public mailing-lists are open lists in which top experts debate with a large community of researchers and users. In this kind of mailing lists, echoes of controversies on private lists meet broader critiques and feed-back from any actors (from research centres, small companies, and so on), who tested implementations.

Our study of the adoption of XML recommendations by the W3C leads us to point out two complementary dimensions of the process. The first one is what we call the privatization of standard-making. This trend is a typical dimension of transnational private governance. This does not mean that public organizations or NGOs are absent, but that they are not able to balance the power of the inter-firm game. The second one is the characteristics of this inter-firm game, which is made both of cooperation to learn together, innovate, and adopt common recommendations and standards, and of competition to be the leader of the emerging new market, what we call 'coopetition' in the second section.

\subsection{The privatization of standard-making}

Assuming the evidence of the privatization of standard-making work supposes not only to observe that companies play a big role in the game, but to measure their involvement and their influence in it.

At a first step of our study, in order to show the variety of participants (in terms of mails posted), the relative importance of the mailing-lists and those of the participants who were active on several lists, we made the following graph (Graph 1). We represent mailing lists as green diamonds, and actors as red circles. The larger the size is, the more important the poster or list is, in terms of number of messages. We have been force to reduce the size of the graph to show its global properties. A larger version of the graph, or zooms on subparts are available on demand. 


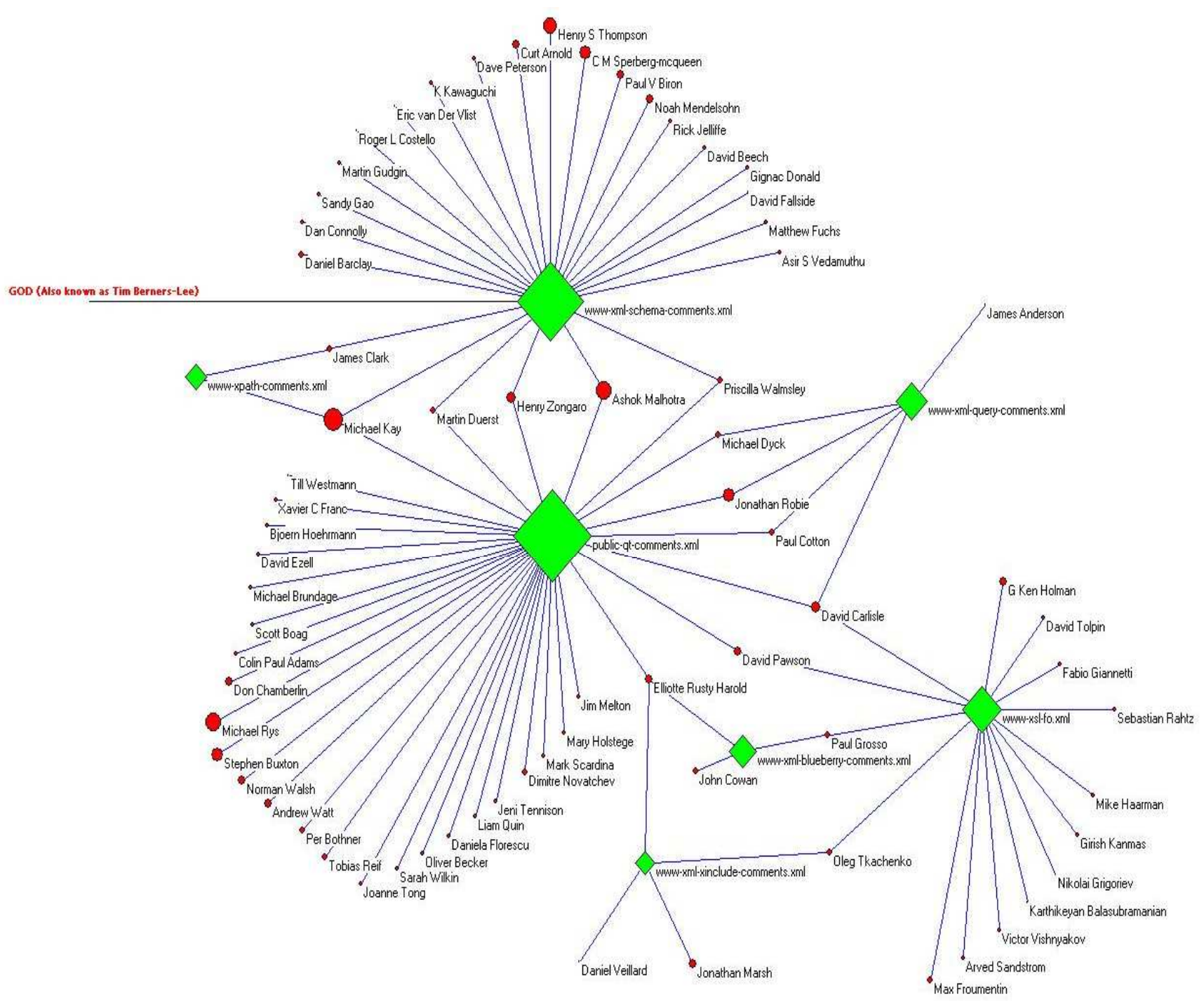

\section{Graph 1. Mapping ${ }^{8}$ of the activism of individuals on the public mailing-lists of the W3C concerning XML standards (using Pajek 1.18)}

The first observation we can make is that mailing-lists are not equivalent in terms of flow (number of messages), but they are all linked by at least two actors. These key actors (14 among 72) are multi-posters. Activism, in terms of posted messages, is of

${ }^{8}$ We would not talk about a social network here, as we are aware of the fact the non inclusion of posters of less than 20 messages in the one or two shorter lists (less than 500 mails for a whole) can represent a bias. As Kossinets (2006) recently showed, fixed choice designs can dramatically alter estimates of network-level statistics. But the author also finds that social networks with multiple interaction contexts may have certain interesting properties due to the presence of overlapping cliques. Our mapping aims at revealing the main individuals of such cliques without measuring the whole interactions within the public lists. 
course mainly due to these types of participants. But we also find sometimes activists on single list. This analysis is not sufficient to lead to anything conclusive, but remains very useful to map the main actors of the whole network and to make hypotheses on their social influence (Marsden, Friedkin, 1993) ${ }^{9}$.

At a second step of the study, our methodology allows us to capture all key institutions involved in the standardization process of the web in a vivid picture. Sociological studies inspired by new institutionalism have been concerned with the ways firms build durable networks and use them to buffer uncertainty, hide or restructure assets, or gain knowledge and legitimacy, by building durable networks (Stark, Vedres, 2006). Powell et al. (2006) are also concerned with innovation in their study about the development of biotechnology. By applying analyses of the structure and dynamics of the networks, and building statistical models to describe their growth through a period of eleven years, they show how the linkages evolve and how this is related to the changing involvement of institutions: universities, research institutes, venture capital, and large and small firms. At the moment, our study is less longitudinal than Powell et al's one. Nevertheless we can give some interesting observations with the work done so far. Observe Graph 2 (on the following page). Green diamonds are once again mailing lists, and blue squares represent institutions. The larger the diamond or square, the more messages posted.

As the graph shows, firms are very active: people from Microsoft, Software AG, IBM, Oracle, Saxonica, have sent more than 1000 messages. To be very rigorous, one has to be cautious with this measure, because some individuals may have had successive memberships fuddled by the synchronicity of the data. Though all institutions are affected by this problem, private ones might be more than public ones. Anyway, mostly represented institutions (those connected with at least 2 mailing-lists) on public mailing-lists are firms: 14 firms in comparison with 8 of other kinds (research centres, associations, NGOs). Even if our measure has to be sharpened by a more longitudinal approach, we can say that the biggest US CS companies play a big role in these mailing-lists. One can note the absence of Google, as well as the quasi-absence of non US firms, if we except Software AG. Research institutes and University play a secondary role.

\footnotetext{
${ }_{9}^{9}$ We of course make a conceptual difference between activism and influence. The only author drawn in red on the mapping, Tim Berners-Lee, invented HTML and founded the web. He is so influent that he is called 'God' by some computer scientists. In our public lists, he only posted one mail. We suppose that his case is somewhat exceptional in our corpus.
} 


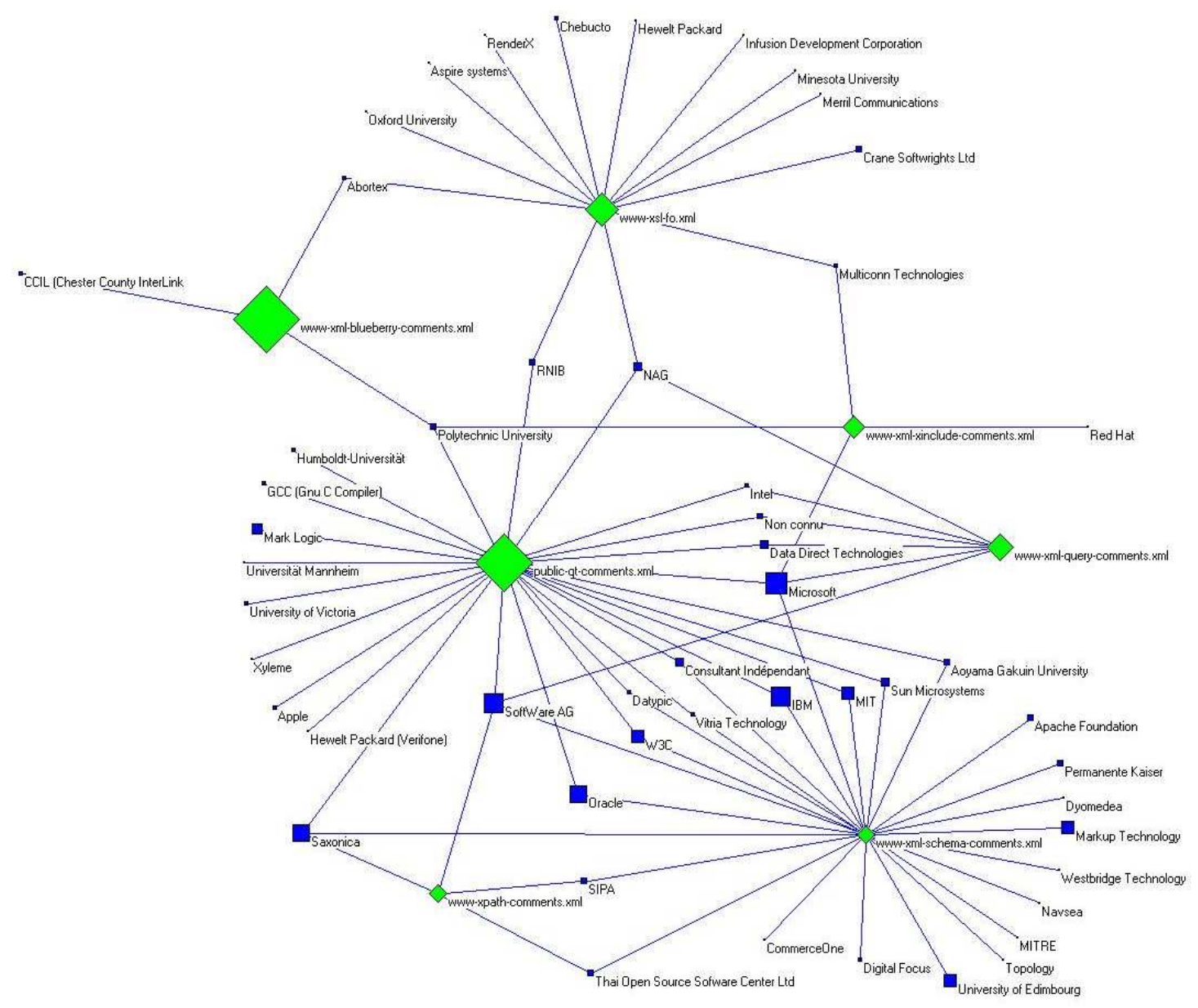

Graph 2. Activism of institutions ${ }^{10}$ on the public mailing-lists of the W3C concerning XML standards (using Pajek 1.18)

Though we still lack very sharp longitudinal analyses, we unsurprisingly notice that the main controversies are generated by main active people on the list, i.e., people from corporations. For example, on the XQuery mailing-list, a long-running controversy appeared about constraints of zero-length string implied by the parent (doc or element) in the construction of text nodes. In this controversy, people from Microsoft insisted on the necessity to simplify the semantics and to optimise text node

${ }^{10}$ Membership of institutions has been here manually reconstituted. 
constructors $^{11}$, while other members insisted on the internal coherence of the Xquery language and bug risks.

Significantly, the most active members of mailing lists mapped in graph 1 are also the most active publishers in the field. Though we don't still have a bibliometric study of publications concerning XML, a (patient) manual research on the available edited documents about XML on the Web makes us notice that these active experts were also the first ones to publish on this topic over time. This links us to the fact that the legitimacy of experts is not only based on their capacity to produce diagnostics and preconizations (Abbott, 1990), but to assume many additional constraints which characterize professional legitimacy: rituals, argumentation, and publicity (Vion, 2007).

Finally, as Sheila Jasanoff (2005) notices, the legitimacy of experts tightly depends on the rules of the game. In the field of XML, being invited by the W3C council to present the ongoing process of a working group at the annual conference is a form of recognition of the technical leadership. Concerning X Query, Mary Fernandez from AT\&T and Paul Cotton from Microsoft have been the most influential speakers in such conferences at the beginning of the process. Mary Fernandez presented the first report of emerging knowledge ${ }^{12}$ and was associated with Paul Cotton to do the third one $^{13}$, before writing the $\mathrm{W} 3 \mathrm{C}$ recommendations on the topics. She was significantly the Keynote speaker of the $1^{\text {st }}$ international conference on XQuery implementation ${ }^{14}$. Paul Cotton presented the second ${ }^{15}$ and the third report (with Mary Fernandez) and was invited by the Unicode Consortium to make a presentation of Xquery ${ }^{16}$. Yet, he did not write of the final Xquery recommendations for W3C, letting his colleague Jonathan Marsh do $\mathrm{it}^{17}$. Other active members of the mailing list edited papers at the very famous SIGMOD Conference ${ }^{18}$. Other papers were published on firms' magazines, whether it resulted of a division of labour within the company ${ }^{19}$, or it meant a lack of institutional resources ${ }^{20}$.

11 For example, Michael Rys, <thd:message date="2004-01-19T21:03:10+02:00" subject="[DM] MSDM-LC2-066", Xquery public mailing-list.

12 Massimo Marchiori and Mary Fernandez, 'Presentation of XML Query', 9th International WWW Conference, Amsterdam, May 2000, http://www.w3.org/2000/Talks/www9-xmlquery/

13 Mary Fernandez and Paul Cotton, 'Presentation of Xpath and Xquery', 11 $1^{\text {th }}$ International Conference (www 2002), Hawaï, May 2002.

${ }^{14}$ Mary Fernandez. (2004) "The Statesman, The General, His Lie tenant, and Her Sentry", Keynote speech at the $1^{\text {st }}$ International Workshop on Xquery Implementation Experience and Perspectives (XIME-P)

${ }^{15}$ Paul Cotton, 'Presentation of XML Query', 10th International Conference (www 10), Hong-Kong, May 2001, http://www.w3.org/Talks/2001/04/www10-Query/

16 Paul Cotton (Microsoft) and Jonathan Robie (Software AG) 'Presentation on XML Query', 20 ${ }^{\text {th }}$ Unicode Conference, Washington, January 2002.

17 This recommandation was signed by Mary Fernández (XML Query WG), AT\&T Labs, Ashok Malhotra (XML Query and XSL WGs), Oracle Corporation, Jonathan Marsh (XSL WG), Microsoft, Marton Nagy (XML Query WG), Science Applications International Corporation (SAIC, Norman Walsh (XSL WG), Sun Microsystems.

18 See for example Peter Frankhauser, 'X Query Formal Semantics. State and Chanllenges', http://www.sigmod.org/record/issues/0109/SPECIAL/frankhauser2.pdf ; Andrew Eisenberg (IBM Westford) and Jim Melton (Oracle) "An Early Look at X Query, http://www.sigmd.org/record/issues/0212/AndrewEJimM.pdf

${ }_{19}$ See for example Don Chamberlin, 'X Query an XML Query Language', http://www.research.ibmcom/journal/sj/414/Chamberlin.pdf, Jason Hunter, 'X is for X Query', http://www.oracle/03

20 See for exampleTim Mathews, Srinivas Pandranji, 'Five Practical X Query aplications', http://www.devx.com/xml/Article/15618/ 
All these publications do not only bring symbolic resources or symbolic capital in the way Bourdieu would mean it. They are ways to improve presentations and to formalize solutions to all problems identified by implementers and expressed through a special mailing system called the 'bugzilla system'. People who are able to make their common work progress through such a writing process are all the more comfortable to face debates in seminars and to formalize recommendations.

\subsection{Corporate rulers at work: a typical game of 'coopetition'}

Standardization processes are made of what sociologists of scientific knowledge call controversies and what political scientists call debates. Let us return to Sheila Jasanoff's hypothesis about the control of scientific innovations by corporate rulers who would have to face the critiques of consuming citizens (Jasanoff, 2003). In this section, we will show that the XML standardization process can be analysed as a process controlled by corporate rulers, in which critiques from consuming citizens are represented by researchers from public centres, whose oppositions are somehow domesticated through formal procedures of debate.

As Goody (1997) contended, writing is not a simple recording of words in various social and technological conditions but favours special forms of linguistic activity and develops certain ways to define and solve the problems: lists, formulas, and tables play a decisive role here. At the end of such a writing process, the common appropriation of a format does not necessarily means exclusive IPR, but has strong incidence on economic competition, as the agreement imposes formal works, designations and uses which exclude de facto alternatives.

This is why the $\mathrm{W} 3 \mathrm{C}$ rules oblige experts to manage open forums on public mailing lists and open seminars of working groups. If such seminars cannot be compared to technology assessment device such as parliamentary ones (Bimber, 1996) or consensus conferences (Joss and Durant, 1995; Marris and Joly, 1996), they ritualize steps of the writing process and can be characterized as punctual debates in the process. By debates, we mean ways by which contradictors sustain formalized points of view through contradictory procedures, in order to convince a public established as a third instance (Manin, 2005). In such seminars, the public is made of all members from research centers, institutes and NGOs, who do not have direct commercial interests in applications. These people must be convinced of the fact that solutions are ways to optimize the processes. At such steps, new alternatives are not welcome. Let us give an example: during a W3C Working Group seminar, two alternative projects of recommendations were presented. When a researcher from a public center proposed a third one, he was answered: 'Is it written? No? So, we have two projects'21. Arguing in such forums does not mean proposing new systems, but expressing support or technical objections to the competing models. This exemplifies the reliance on technical and professional knowledge of private actors which characterizes transnational private governance (Graz, Nölke, 2007).

\footnotetext{
${ }^{21}$ Interview with a member of the XQuery working group, January, 2007.
} 
Inside such kind of governance, activism on public mailing lists is a way to support and mobilize critiques addressed to formalized solutions. This means that the most active people on mailing lists might not be the ones who control the writing process. We tested the correlation between activism and signing final versions of official texts (see Table 1).

\begin{tabular}{|c|c|c|c|c|c|c|c|c|}
\hline Institution & $\begin{array}{c}\text { Type of } \\
\text { Instituti } \\
\text { on }\end{array}$ & $\begin{array}{c}\# \\
\text { Individual } \\
\mathrm{s}\end{array}$ & $\begin{array}{l}\text { Total } \\
\text { Text }\end{array}$ & $\begin{array}{c}\text { W3C } \\
\text { Recommendatio } \\
\text { ns }\end{array}$ & $\begin{array}{l}\text { W3C } \\
\text { WG } \\
\text { Notes }\end{array}$ & $\begin{array}{c}\text { Working } \\
\text { Drafts }\end{array}$ & Activism & $\mid \begin{array}{c}\text { Rank } \\
\text { of } \\
\text { activis } \\
\text { m (out } \\
\text { of 51) }\end{array}$ \\
\hline IBM & Corp & 11 & 13 & 8 & 2 & 3 & 1401 & 3 \\
\hline Oracle & Corp & 8 & 13 & 6 & 1 & 6 & 1289 & 4 \\
\hline AT\&T & Corp & 2 & 7 & 4 & & 3 & - & _ \\
\hline $\begin{array}{l}\text { Data Direct } \\
\text { Technologies }\end{array}$ & Corp & 1 & 6 & 2 & 2 & 2 & 363 & 11 \\
\hline Microsoft & Corp & 5 & 6 & 4 & & 2 & 1780 & 1 \\
\hline BEA Systems & Corp & 2 & 3 & & & 3 & - & _ \\
\hline Infonyte $\mathrm{GmbH}$ & Corp & 1 & 3 & 1 & 2 & & - & - \\
\hline $\begin{array}{l}\text { Library of } \\
\text { Congress }\end{array}$ & Gov & 1 & 3 & & & 3 & _ & - \\
\hline Unknown & n.a. & 2 & 3 & 3 & & & - & - \\
\hline Sun Microsystems & Corp & 1 & 3 & 3 & & & 300 & 12 \\
\hline $\begin{array}{l}\text { University of } \\
\text { Edimbourg }\end{array}$ & Uni & 2 & 3 & 2 & 1 & & 591 & 7 \\
\hline Mark Logic & Corp & 2 & 2 & & & 2 & 418 & 10 \\
\hline Saxonica & Corp & 1 & 2 & 2 & & & 1062 & 5 \\
\hline $\begin{array}{l}\text { University of } \\
\text { Venice }\end{array}$ & Uni & 1 & 2 & & 2 & & _ & _ \\
\hline Brown University & Uni & 1 & 1 & 1 & & & - & - \\
\hline CommerceOne & Corp & 1 & 1 & 1 & & & 42 & 37 \\
\hline INRIA & Uni & 1 & 1 & & & 1 & - & - \\
\hline Inso & Corp & 1 & 1 & 1 & & & - & - \\
\hline Invited Expert & n.a. & 2 & 1 & & & 1 & - & - \\
\hline $\begin{array}{l}\text { Kaiser } \\
\text { Permanente }\end{array}$ & Org & 1 & 1 & 1 & & & _ & - \\
\hline MIT & Uni & 1 & 1 & & 1 & & $57 \overline{1}$ & $\overline{8}$ \\
\hline Pisa University & Uni & 1 & 1 & & & 1 & - & _ \\
\hline SIAC & Corp & 1 & 1 & 1 & & & - & - \\
\hline W3C & Org & 1 & 1 & & 1 & & 615 & 6 \\
\hline WebMethods & Corp & 1 & 1 & & & 1 & - & _ \\
\hline
\end{tabular}

Table 1. Test of the correlation between activism and signing final versions of official texts 
First of all, the table shows that the correlation is not absolute. Some of the institutions associated to technical preconizations (recommendations) do not appear in our measure of activism. This can be explained mainly by two ways:

- the lists we used are public, but in some cases preconizations are decided in private lists for WG members only. As we cannot legally access to these private lists, some individuals and institutions are not taken into account ${ }^{22}$

- some of the individuals actors we take into account hold multiple functions. For example, Michael Kay (Software AG and Saxonica) only publish one membership (Saxonica) when authoring official preconizations.

But the major result of this text concerns activism from Microsoft's experts. Though some of them signed some of the major recommendations, such as XML schema or XQuery, the Microsoft team is all the more active on public lists that it is out of some co-authors' networks. When drawing the structural network of co-authoring of W3C final texts, we observe the central role played by experts from IBM and AT\&T.

${ }^{22}$ W3C now incites actors to debate on public lists, what will ease our future studies. 


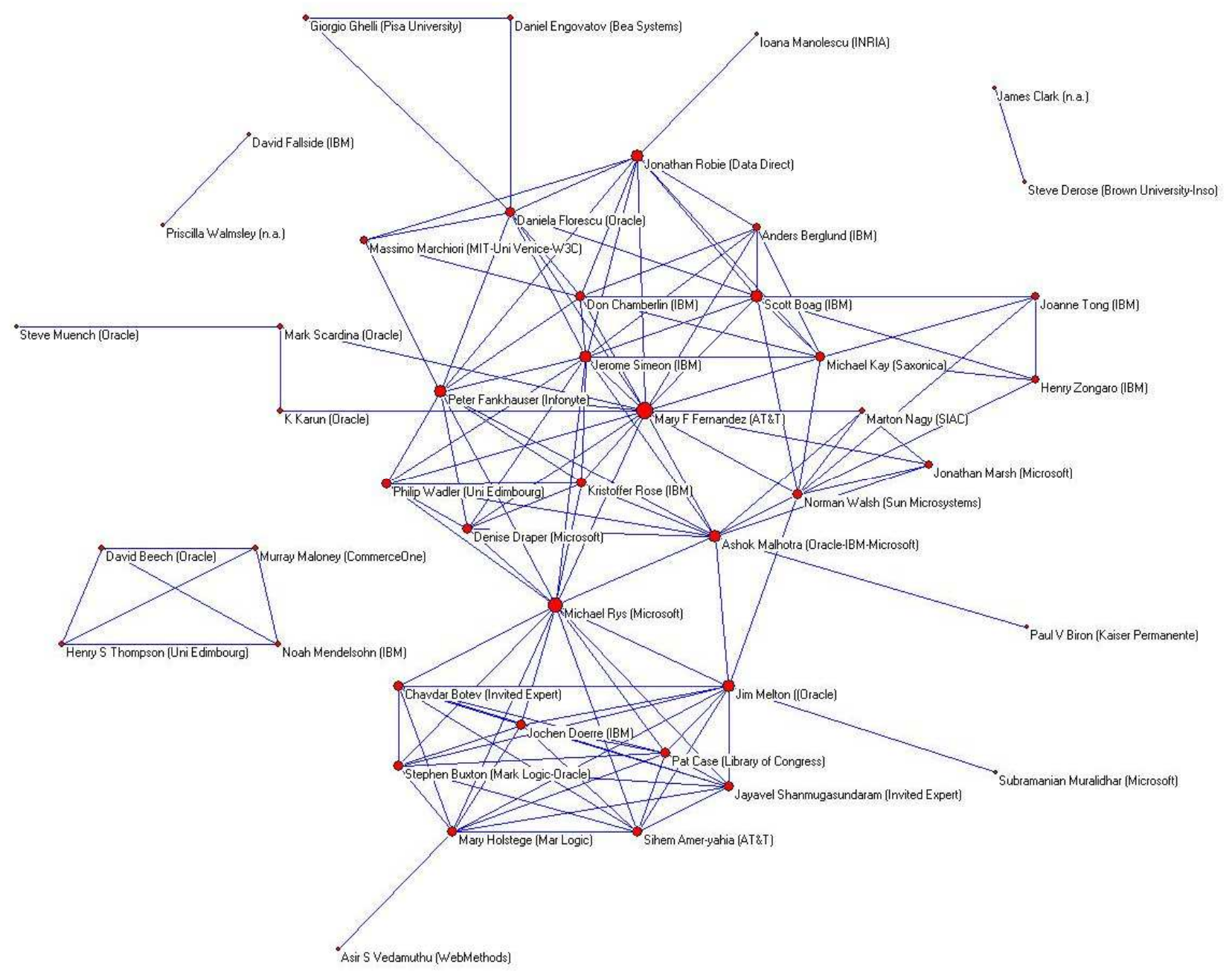

Graph 3. Structural network of co-authoring of W3C final texts on XML

Retrospectively, the effort to get included in the writing process by addressing and mobilizing critiques in controversies such as the one about nodes of texts seems to be hard to sustain.

To conclude, we have shown that small networks of experts can be identified, though the debates seem to be very open. Moreover, the distinction between 'corporate rulers' and consuming citizens in the $\mathrm{W} 3 \mathrm{C}$ forums is not that relevant: We have shown that consuming citizens are not physically present, but can on the one hand be represented by University researchers, corporate experts, as virtual supports to critical arguments, that could be of public and general interest. On the other hand, consumers are also often referenced by industrials, that explain that their 'clients' have certain expectations, or demands, and wish to use the software in specific ways. Therefore, although the consumer is not directly present, and posting to the mailing list, this does not mean that there is no debate and no public. Debates are ways to ritualize the 
selection between alternatives. These alternatives are key elements of the process of 'coopetition', because they are always likely to provide competitive advantages for dominating the emerging new market. We have assumed that 'coopetition' and 'corporate rule-making' are two central dimensions of transnational private governance.

In their work on TPG, Graz and Nölke (2007) insist on the limits of such a mode of governance. According to them, they boil down to the limited ability to solve large societal problems, and the limited transparency and accountability of firms, which makes the game more fragile than it seems. In our case study, the next step of the standardization process illustrates the difficulties to solve problems when major trade interests are immediately at stake. The turn from loyalty in inter-firms' cooperation to a more brutal use of force reveals the increasing heaviness of coordination mechanisms and the emergence of monopolistic inclinations as soon as technical solutions to exploit applications of a new format reach maturity.

\section{BEYOND TRANSNATIONAL PRIVATE GOVERNANCE: STRUGGLES AND CRITIQUES}

As Graz and Nölke (2007) pointed out, the changing organization of markets is one of the exchange conditions of the emergence of transnational private governance. In a context where open source software is expanding to face Microsoft's quasi-monopoly on mass-consuming software markets, one can understand the game of coopetition within the $\mathrm{W} 3 \mathrm{C}$ and the emergence of new strategies to convert the writing of technical recommendations into open standards for XML applications. Unsurprisingly, IBM, whose experts were co-leaders in the working groups, developed an offensive strategy which forced Microsoft to react by many ways. This struggle is all the more important that it confronts two business models and points out the limits of TPG.

\subsection{From specifications to applications: the leadership of IBM}

In the W3C's device of working groups, the work on XML was organized as a cooperative work between groups, in particular the XML schema group, which guaranteed the interoperability between XML and other languages, and between XML and its specifications. Some people from public research centres were mandated by their institution to ease the coordination between groups. W3C executives are furnished by MIT Computer Science and Articial Intelligence Laboratory, the European Research Consortium for Informatics and Mathematics (Mainly supported by French INRIA) and Keio University (Japan). Nevertheless, most of the standardization work is conducted by W3C working group, where experts from firms (both large and small) dominate. Let us nonetheless insist that participation in a working group bears a human cost: participants devote most often a full time job to this task, which is easier for large structures. Microsoft experts were particularly active in the XML schema group, so they could expect to play a central role in the process. Nevertheless, the growing importance of the specifications of the XML language made impossible to control the whole process from the sole XML schema group. Specifications like the XQuery and XPath languages, or even interoperability with the 
former XSL developed very quickly, as we saw with XQuery. By examining the structure of coauthoring of all W3C final texts linked to XML (graph 3. supra), we notice that IBM, by cooperating with Oracle and AT\&T, gained a central position in the writing process.

On the basis of the W3C work, the Open Office community elaborated an open and interoperable format applying XML: the Open Document Format (ODF). ODF was first accepted as a standard by the OASIS consortium, in which Sun and IBM play a leading role. Before final recommendations were published by the W3C, OASIS proposed quickly the ODF to ISO, in order to get it accepted as a universal standard. The ISO procedure led in 2005 to a unanimous acceptation of ODF as a new ISO standard (ISO 26300). Immediately afterwards, IBM commercialised some new, freely downloadable software based on ODF, under the label Lotus Symphony 23. This illustrates IBM's long time strategy ${ }^{24}$, based on a business model in which services prevail on sale of mass-consuming software.

Unsurprisingly, IBM managers had decided to promote an open format and to sell new services attached to free software as quickly as possible, in order to benefit from the advantage gained in the W3C process, and to impeach Microsoft's usual business model of developing its own XML software. As noticed in our previous reflexion on standards (Dudouet, Mercier, Vion, 2006), applying a standard does not necessarily means monopolizing a format, but it gives a technological advance in the new market created by it, so that firms who compete have to bypass technological barriers by promoting new standards or to develop new applications from the standardized format. In any case, this means that the format is temporarily monopolized by a social group, as we will now see from the perspective of the relations between Microsoft, IBM and Google about Microsoft's development of Open XML.

\subsection{Assuming competition by playing the consuming citizen's critique: Microsoft's defensive strategy}

As the Redmond Company was late in commercialising its mass-consuming software application of XML, Microsoft experts elaborated a defensive strategy which was based on promoting an alternative open source software application of XML: Open XML. In this application, most of the XML application would be in Open source, as in ODF, and Microsoft would develop its own user-friendly software on this basis in its Microsoft Office 2007, the Office Open XML (OOXML). Microsoft engaged huge means in the promotion of this alternative format in all countries whose national standardization agencies would vote in ISO, in order to benefit from the Fast track procedure, a way to accelerate the approbation by ISO.

At the beginning of 2007, a big struggle between Microsoft and IBM began, about the necessity to adopt a new open format. In all national agencies, experts from IBM began to convince experts that Open XML would not provide better optimisations

\footnotetext{
${ }^{23}$ http://www.theinquirer.fr/2007/09/22/ibm

${ }^{24}$ Let us note that IBM has used a similar strategy of public vs. proprietor in the past, back in 1980, when it chose to make the BIOS of their new machine (the IBM-PC) public, and therefore legally possible for other manufacturers to build clones, in order to counter Apple. Nearly 30 years later, PCs vastly dominate the computer market, and this has been the case for over 15 years.
} 
than ODF. In February 2007, Microsoft published an open letter on its company's site, in order to critique IBM's strategy of stalling the standardization process of Open XML at ISO. During this campaign, IBM's strategy was characterized by Microsoft mangers as "using standardization processes in order to limit market choices at commercial ends, and this, without taking into account the negative impact on consumers' choices and technological innovation." 25

In September 2007, the Open XML proposition was refused by the ISO Committee. To be adopted, a standard must be accepted by $66 \%$ of national agencies and must not be refused by more than $25 \%$ of them. Actually, the first vote established $53 \%$ in favour of Open XML and $26 \%$ against the new format (including influent countries like India, China, France, United Kingdom).

For the first time in its history, Microsoft's strategy consisted on playing the consuming citizen's critique they had faced for years, to challenge IBM's advance. As we will see now, such a strategy and such a commercial struggle changed the course of controversies, by turning them into critique, and changing the relevant resources to sustain them.

What is interesting at this step is that all positive resources of transnational private governance (loyalty, credibility, formal procedures and leverage power) can adopt the darker side of inter-firm rivalry: critique, use of force, informal strategies and corruption, financial fighting.

\subsection{ISO standardization and the need for new resources and new rules}

Various resources were mobilized during this ISO struggle, which ended in Spring 2008, with a positive vote for Microsoft at the end of the second round. Countries like United Kingdom finally turned there vote, while opposites like Indians enlightened their critics. ISO rules are very different from the W3C's ones, because voters are not individual experts, but official experts mandated by national agencies to support their approbation (conditional or unconditional) or disapprobation. Let us stress that national agencies are not necessarily public agencies, most of them like Afnor are hybrid or totally private. During the process, Microsoft had to face disapprobation from influential countries such as India, China or France. Even in the United States, the national experts' approbation was highly conditioned. The first strategy of Microsoft experts had been to promote the Open XML standard in national agencies using technical argumentation, which is often the case in such forums. IBM's experts' counterarguments in these forums made critiques increase and overlap forums.

\section{Irony}

The first way for Microsoft to face IBM's critiques in national agencies was to argue on processing optimizations favoured by Open XML. Against the argument that ODF would be sufficient, Microsoft experts pointed that Open XML would be "more open" than ODF; this generated ironical critiques about Microsoft's longstanding

25 Tom Robertson and Jean Paoli, "Interoperability, Choice and Open XML", edited on Microsoft Web site, February 14. 
strategy of monopolization. But this argument could also be return to IBM's experts as "even worse monopolizers" than the Microsoft ones.

As narrated by an anonymous observer of the AFNOR debate ${ }^{26}$, another step in irony consists of repeated inter-individual mezza voce conversations between Microsoft experts using terms like: 'ODF is really bullshit!' This kind of irony echoes climates of farce (Picart, 1994) observed in famous controversies such as the Benveniste-Maddox affair concerning homeopathy. As noticed by other commentators of this affair (Fadlon, Lewis-Epstein, 1997), such a climate reveals the shift between forms and modes of rejection in the course of the controversy. Shifting from implicit to explicit modes of rejection is often observed when it runs outside the boundaries of the scientific community; the jump from the W3C, constituted of computer science experts, to the more heterogeneous ISO perfectly illustrates this.

Allies

In order to support their strategy, both Microsoft and IBM had to gain new allies in the struggle. Both lobbied private North American IT consortiums. Microsoft's strategy was to promote Open XML in ECMA, composed of Adobe Systems inc., Avaya, Barclays Capital, Canon, Ericsson, Fujifilm, Fujitsu, Global graphic, Hewlett Packard, Hitachi, IBM, Intel, Konica Minolta, Lexmark, Microsoft, Panasonic, Philips, Pioneer, Ricoh, Sony, Statoil, Toshiba, Xerox, Yahoo!. The ECMA support intended on the other hand to build the Open XML solution's credibility in the ISO process, by insisting on the fact applications would not be monopolized by only the Microsoft Corporation. This strategy helped Microsoft gain new support in the second phase of the Fast track procedures: from about 30 votes of approbation on the 66 needed, Open XML jumped to 51 in September. In September, IBM also mobilized new allies through the Oasis consortium, enrolling Google in the struggle. Google, who had been quasiabsent from the W3C process, see section 2) had been working with IBM, the main rival of Open XML in ISO.

\section{Money and lobbying}

A lot of money was invested in the promotion of Open XML, since the standardization process delays the commercialisation of the OOML. In Spring 2007, Microsoft had to face an affair in Sweden, in which one of his experts was charged of corrupting members of the national agency. This led to critiques on Microsoft's aggressive strategy expressed in blogs and journals. Time and money had to be spent to publish counter-critiques of IBM's strategy and partiality of some national votes such as the AFNOR's one. Even though Open XML was standardized by ISO in Spring 2008, one can see that IBM's advance in the W3C and ISO processes generated high costs for the Redmond Company.

In each country, Microsoft sent experts and advocates to national committees, in order to make them change their vote. Diaz (2008) analysed various trajectories of national votes. He focused on the cases of France, UK, Sweden and Venezuela, and described all the influential games including corruption in Sweden, political pressure on the national agency in France, unexplainable turns at the British Standards

${ }^{26}$ http:/ / linuxfr.org/ MrLapinot/25173.html 
Institute, etc. In every case, it is clear that debates were not longer technical, but fights on procedure, external pressure from more or less orchestrated consumers' critiques, political injunctions, and so on.

Deeper inquiries should be made about the whole voting process in ISO during the Open XML fast track procedure. Many obstacles to such an inquiry remain: secrets, confidentiality of the debates, etc. On the contrary, W3C's current reflexion concerns ways of making their debates more transparent. Even though we still suffer from a lack of information, one can see that the contrast between the TPG process in W3C and the more classical competition through the ISO process is evident. What does this mean for the TPG model?

\section{What's new beyond transnational private governance?}

As Jasanoff (2005) points out: 'At a time when the vast majority of public decisions involve sizeable components of technical analysis, any change in the relative positions of scientific and political judgment carries with it a displacement in the exercise of power, with possible consequences for participation, deliberation and accountability. Now, no less than in 1960s, when Yale University political theorist Robert Dahl used it as the title of his seminal treatment of democracy, the question at the heart of politics remains, "Who governs?" (Dahl, 1961). A difference, however, is that technical decision-making is now more visibly and continuously a part of the playing field of politics.

The fight between Microsoft and IBM finally implied many political games in a fight between two business models: products versus services. If IBM had succeeded to impose ODF as the single standard for XML, Microsoft's managers would have had to change their own business model focused on the sale of software towards a more service-based strategy. In this case, Microsoft would certainly have suffered from important difficulties to sell OOXML. IBM would have been in optimal position to offer customized implementations of XML through the Lotus Symphony basis of services.

It is still too early to verify the hypothesis of a longstanding monopolization of the format, but we observe that major software applications of XML have been somehow temporary monopolized by IBM. Time will let us know whether OOXML were not likely to become the next dominant mass-consuming format through the development of the next generation of Microsoft's Systems. After opportune calls for a new organization of markets through open standards and nothing more than rhetorical stress on consuming consciousness, more classical monopolistic achievements might be the next sequence of the game. This would be all the less surprising since standardization processes produce durable annuity for winners.

\section{CONCLUSION}

In this article, we have shown that a preliminary analysis of mailing lists, and recommendations leads to the confirmation of the hypothesis that standards are elaborated within a structure of transnational private governance: we see that industrial companies dominate the making of standards. Moreover we have stressed that the control of the writing process in constitutive forums like W3C are key 
advantages for firms, and that changing rules in the standardization of applications imposes to mobilize new resources like irony, external critique, money, and commercial alliances. In particular, this XML process shows that IBM's advance impeached Microsoft's traditional strategy of commercial domination through its Office software, which could be either an episode of the longstanding competition between CS firms or a crucial turning point in it - this is all too early to say.

\section{REFERENCES}

Аввотт A. (1995) "Sequence Analysis", Annual Review of Sociology, 21:93-113.

AввотT A., Barman E. (1997) "Sequence Comparison via Alignment and Gibbs Sampling", Sociological Methodology, 27: 47-87.

AвbOtT A., Hrycak A. (1990) "Measuring Resemblance in Social Sequences", American Journal of Sociology, 96:144-185.

Aввотt A., Tsay A. (2000) "A Sequence Analysis and Optimal Matching Methods in Sociology", Sociological Methods and Research, Vol 29, n¹, 3-33

Auray N., Conein B., Dorat R., Latapy M. (2007) "Multi-level analysis of an interaction network between individuals in a mailing-list", Annals of Telecommunications, Vol. 62, n³-4, March-April.

Beaudouin V., VelKovska J. (1999) "Constitution d'un espace de communication sur internet", Réseaux, n 97, 123-177.

Beaudouin V., Fleury S., Pasquier M., Habert B., Licoppe C. (1999) "Décrire la toile pour mieux comprendre les parcours", Réseaux, n 116 , 19-51.

BENEDEK W., KETTEMANN M., BAUER V. (2008) Internet Governance and the Information Society. Global Perspectives and European Dimensions, Eleven International Publishing, Utrecht.

BERKOWITZ S.D. (1982) An Introduction to structural analysis, Toronto Butterworth.

BIMBER B. (1996) The politics of Expertise in Congress, Albany, NY, SUNY Press.

BIMBER B. (1998) 'The Internet and political transformation: populism community and accelerated pluralism', Polity, vol. 31, n¹, 133-160.

BorgatTI, S.P., FOSTER, P. (2003) The network paradigm in organizational research: A review and typology. Journal of Management. 29(6): 991-1013

BRANDENBURGer A., NALEBUfF B.J., (1995) “The right game: use game theory to shape strategy", Harvard Business Review, July-August, 57-71.

Brunsson N., Jacobsson B. (2002) A World of Standards, Oxford University Press.

Buckner K., Gillham M. (1999) "Using E-Mail for Social and Domestic Purposes", IFIP Conference Proceedings, Vol. 173. 
CAREN N., PANOFSKI A. (2005) "TQCA", Sociological Methods and Research vol 34, n², 147-172.

CARLEY K.M. (1996) "Artificial intelligence within sociology", Sociological Methods and Research, Vol. 25, n 1 3-30.

Chesbrough H.W., Appleyard L.L. (2007) "Open Innovation and Strategy", California Management Review, Vol 50, n¹ 57-76.

Colazzo D., Dudouet F.-X. ; MANolescu I., NGuyen B. ; Senellart P., Vion A.(2008) «Data Warehousing: Analysing Web Data Application to the Study of the W3C Standardization Process » submitted to Sociological Methods and Research.

DiAZ P.A. (2008) Open XML à l'ISO, les trajectoires de vote de la France, le Royaume-Uni, le Venezuela et la Suède, Master dissertation, University of Lausanne. Directed by J.-C. Graz.

Di Maggio P., HargitTai K., Newman W., Robinson J. (2001) 'Social implication of the Internet', Annual Review of Sociology, vol. 27, 307-336.

DJELIC M.L., SAHLIN-ANDERSSON K. (2006), «Introduction: A world of governance: The rise of transnational regulation ", in Transnational Governance: Institutional Dynamics of Regulation, Cambridge University Press.

Doreian P. (2001) "Causality in social network analysis", Sociological Methods and Research, vol 30, n¹, 81-114.

Dudouet F.-X., Manolescu I., NGuYen B. Senellart P., "XML Warehousing Meets Sociology", Proceedings of the IADIS International Conference on the Web and Internet, Lisbon, Portugal, October 2005

Dudouet F.-X., Mercier D., ViOn A. (2006) "Politiques de normalisation. Jalons pour la recherche empirique", Revue Française de science politique, vol 56, n 3, June, 367392.

FADLON J., LEWIS-EPSTEIN N. (1997) 'Laughter spreads: Another perspective on boundary crossing in the Benveniste affair', Social Studies of Science, Vol. 27, 131-141.

GRAZ J.-C., NOLKE A. (2007) Transnational private governance and its limits,, Routledge.

HALl R.B., Biersteker T. (eds) (2002) The Emergence of Private Authority in Global Governance, Cambridge University Press.

Hox J.J., KREFT I.G.G. (1994) "Multilevel analysis methods", Sociological Methods and Research, vol 22, n³, 283-299.

Huisman M., SNijDers T. (2002) "Statistical Analysis of Longitudinal Network Data with changing composition", Sociological Methods and Research, Vol 30, n² 2, 425-454.

IANSITI M., MAC CORMACK A. (1997) 'Developing products on Internet Time', Harvard Business Review, 9/10, vol. 75, n5, 108-117.

Jansen I., Van den Troost A., Molenberghs G., Vermulst A.A., Gerris J.R.M. (2006) "Modeling Partially Incomplete Marital Satisfaction Data", Sociological Methods \& Research, 8,vol. 35: pp. 113 - 136. 
JASANOFF S. (2001) 'Image and Imagination: the Emergence of Global Environmental Consciousness', in Miller C.A. AND EDWARDS P.N. (eds.) Changing the Atmosphere: Expert Knowledge and Global Environmental Governance, Cambridge, MIT Press.

JASANOFF S. (2003) 'In a constitutional moment', in JOERGES B., NOWOTNY H., Social Studies of Science and Technology: Looking Back, Ahead, Dordrecht, Kluwer Academic Publishers155-180.

JASANOFF S. (2004) 'Ordering Knowledge, ordering society', in JASANOFF S. (ed.) States of Knowledge. The co-production of Science and Social Order, New York, Routledge.

JaSANOFF S. (2005) 'Judgment Under Siege: The Three-Body Problem of Expert Legitimacy', in MAASEn S., WeInGART P. (eds.) Democratization of expertise? Exploring Novels forms of Scientific Advice in Political Decision-Making, Dordrecht, Springer.

JeNNINGS K., ZEITNER V. (2003) 'Internet and Civic engagement: a longitudinal analysis', Public Opinion Quarterly, Vol. 67, n³ 311-315.

Jones, C., Hesterly, W. S., BorgatTI, S. P. (1997) 'A general theory of network governance: Exchange conditions and social mechanisms', Academy of Management Review, 22(4): 911-945.

JULLIEN N., ZIMMERMANN J.-B. (2006) «New approaches to intellectual property: from open software to knowledge-based industrial activity ", in Patrizio BIANCHI P., LABORY S. International Handbook of industrial policy, Edward Elgar.

Joss S., Durant J. (1995) Public Participation in Europe. The role of consensus conferences in Europe, London, Science Museum.

Kavassalis P., SOlomon R.J., Benghozi P.-J. (1996) 'Open Standards and interoperability. New learning modelsfor electronic communications', Revue d'économie industrielle, $\mathrm{n}^{\circ} 1,163-185$.

KLEIN H, KLEINMANN D.L. (2002) 'The social construction of technology: structural considerations', Science, Technology and Human Values, Vol. 27 (1), Winter.

KLEINMANN D.L. (1998) 'Untangling context: understanding a University laboratory in the commercial world', Science, Technology and Human Values, Vol. 23, 285-314.

KLEINWÄCHTER W. (2007) 'Internet Governance and governments: enhanced cooperation or enhanced confrontation ?' Communications Law, vol. 12, $\mathrm{n}^{\circ} 4,111-118$.

KORFF F., GELLNER W. (1994) Demokratie und internet, Baden-Baden, Nomos.

Kossinets G. (2006) "Effects of missing data in social networks", Social Networks, Volume 28, Issue 3, 1 July 2006, 247-268. 
LATOuR B. (1987) Science in action: How to follow engineers in society. Milton Keynes. Open University Press.

LASCOUMES P., LORRAin D. (2007), 'Trous noirs du pouvoir. Les intermédiaires de l'action publique', Sociologie du travail, Vol. 49, 1, January-March, 1-9.

LAZER D. (2007) 'Presentation of the program on networked governance', http://www.hks.harvard.edu/netgov/html/index.htm

LESNARD L., SAINT-POL T. (de) (2004) Introduction aux méthodes d'appariement optimal (Optimal Matching Analysis), Document de travail INSEE, n² 2004-15, 30 p.

MARRIS C., JOLY P.-B. (1999) 'Between consensus and citizens : public participation in technology assessment in France', Science Studies 12 (2), 3-32.

MARSDEN P.V., FrIEDKIN N.E. (1993) "Network studies of social influence", Sociological Methods and Research, vol 22, n¹, 127-151.

NalebufF B.J., Brandenburger A.M. (1997) "Coopetition: competitive and cooperative business strategies for the digital economy", Strategy and Leadership, November-December, p. 28-35.

NAlebuff, B. J. ET A. M. Brandenburger (1996) : Co-opetition, London : HarperCollinsBusiness.

NÖlKe A., PERRY J. (2007), « The Power of Transnational Private Governance:

Financialization and the LASB », in Business Power and Global Govenance, Volume 9, Issue 3, 2007

PARAPONARIS C. (2008) 'Réseaux de valeur et innovation', Work in progress, Université de Savoie.

PATtBerg P. (2005) «The Institutionalization of Private Governance : How Business and Nonprofit Organizations Agree on Transnational Rules », in Governance: An International Journal of Policy, Administration, and Institutions, Vol. 18, No. 4, October.

PICART C. J. (1994) Scientific controversy as a farce. The Benveniste-Maddox Counter Trials, Social Studies of Science, Vol. 24 (1), 7-37.

PisANO, G.P, TEECE, D.J. (2007) "How to Capture Value from Innovation : Shaping Intellectual Property and Industry Architecture", California Management Review, Vol.50, n¹, 278-296.

Powell W.W., White D.R., Koput K.W., Smith J.O. (2006), "Growth of interorganizational collaboration the Life Sciences", American Journal of Sociology, Volume 111 Number 5 (March): 1367-1411

SHAPIN S, SCHAFFer S. (1985) Leviathan and the Air Pump: Hobbes, Boyle, and experimental life, Princeton, Princeton University Press. 
Stovel K, Savage M, Bearman P (1996) « Ascription into Achievement: Models of Career Systems at Lloyds Bank, 1890-1970», American Journal of Sociology, September, 358-399.

StARK D., VeDres B. (2006) "Social Times of Network Spaces: Network Sequences and Foreign Investment in Hungary", American Journal of Sociology, Volume 111, Number 5 (March).

SunsteIn C. (2007) Republic.com.2.0., Harvard University Press.

TAMM-HALlSTRÖM K. (2001) "In Quest of Authority and Power: Standardization Organizations at Work", Scancor Workshop: Transnational regulation and the transformation of states California, USA 22-23 June.

TAMM-HALLSTRÖM K (2004) Organizing International Standardization - ISO and the IASC in Quest of Authority, Cheltenham United Kingdom 2004.

TAUBMAN G. (2003) 'State sanctionned surfing, limited connectivity and varied access to Cyberspace in non democracies', Asian Perspective, vol. 27, n 2, 105-140.

VION A., DudoueT F.-X. (2007) «Debating on standards, XML from W3C controversies to the ISO struggle » Society for Social Studies of Science 2007 (4S) Annual Meeting, Montreal.

WERBACK K. (2000) 'Syndication: the emerging model for Business in the Internet Era', Harvard Business Review, 5/6, Vol. 78, n 3, 85-93.

\section{WEBSITES}

QizX Open: a free-source Xquery Engine. Available at http://www.axyana.com/qizxopen/

Active XML reference: http://www.axml.net/

IEEE Standardization Working Groups Areas Available at http://grouper ieee org/groups/index html

The KelKoo comparative shopping engine Available at http://www.kelkoo.com

The Linux Kernel mailing list archive Available at http://www.uwsg.indiana edu/hypermail/linux/kernel

The W3C Math Home Page Available at http://www.w3.org/Math

The Web Content Accessibility Guidelines Working Group Available at http://www .w3.org/WAI/GL

XML Path Language Available at http://www.w3.org/TR/xpath

The W3C XQuery mailing list (access restricted to W3C members) Available at http://lists.w3.org/Archives/Member/w3c-xml-query-wg

XQuery products and prototypes Available at http://www.w3 .org/XML/Query\#Products 
The XQL query language Available at http://www.w3.org/TandS/QL/QL98/pp/xql.html

The W3C XQuery Working Group Available at http://www.w3.org/XML/Query

TDA is available at http://steinhaus.stat.ruhr-uni-bochum.de/binaries.html, the interface Win TDA at: http://www.tufts.edu/ kschmi04/research/ and the manual at http://www.stat.ruhr-uni-bochum.de/tman.html

The Extensible Stylesheet Language Family Available at http://www.w3. org/Style/XSL

Available at http://search.cpan.org/ simon/Mail-Thread

Action Concertée Incitative Normes Pratiques et Régulations des Politiques Publiques Available at: http://www-rocq.inria.fr/gemo/Gemo/Projects/npp/index

XML Spy Available at: www altova com [52] XS m: the XML Summary Drawer Available at http://www-rocq.inria.fr/gemo/Gemo/Projects/SUMMARY

Zawinski J Message threading Available at http://www.jwz.org/doc/threading.html

http://www.theinquirer.fr/2007/09/22/ibm offre a son tour open office.html http://www.openmalaysiablog.com/2008/03/the-last-tap.html http://www.iht.com/article/2006/12/07/yourmoney/msft.php http://www.groklaw.net/staticpages/index.php?page $=20051216153153504$ http://www.search.Blossom.com/query/320?key $=$ ooxml\&submit= $=$ search http://www.consortiuminfo.org/standardblog/blogs.msdn.com/brian-jones/ http://www.heise.de/newsticker/suche/?run=search\&g=ooxml\&search submit=los $\underline{021}$

http://www.microsoft.com http://www.openxmlcommunity.org http://www.afnor.org http://www.fondonorma.org http://www.gobiernoenlinea.ve http://www.iso.org http://www.ecma-international.org http://www.oasis-open.org http://www.blog.bureado.com.ve http://fr.wikipédia.org/wiki/Format_ouvert http:// aporrea.org 